\title{
REFLECTION
}

\section{You Will Have a New Life}

\section{Adi Finkelstein, $P b D$}

Department of Nursing, Faculty of Life and Health Sciences, Jerusalem College of Technology, Jerusalem, Israel
Conflict of interest: author reports none.

\section{CORRESPONDING AUTHOR}

Adi Finkelstein Jerusalem College of Technology Campus Tal Beit Hadfus 7 Jerusalem, Israel 9548311 adilan@netvision.net.il

\begin{abstract}
This narrative presents my personal reflections as a medical anthropology researcher, and my journey as a chronic patient suffering for 30 years from ulcerative colitis. My surgeon promised me "a new life" after recommending a total colectomy 20 years ago. Indeed, a new life did begin following surgery, but I find I must renegotiate the challenges and rewards of this new life nearly every day.
\end{abstract}

Ann Fam Med 2018;16:166-167. https://doi.org/10.1370/afm.2181.

Treached a pivotal year in my life in 1997. I had already been suffering from ulcerative colitis since the age of 18 . During those 11 years I developed a complex routine to manage the symptoms, which included bleeding, severe pain and swelling in my lower abdomen, gas, and nausea. I was an undergraduate student and working full-time as a life guard and swimming coach. I took pills and rectal suppositories on a daily basis, followed by enemas every night. Managing the symptoms was challenging, spending long work shifts in a bathing suit and shouldering a lot of responsibility. I was constantly afraid—when will the next disease eruption arise? How long will it last? Will I be able to control the symptoms in time and avert an embarrassing situation? I was living parallel lives-one present in the world while the other was constantly attending to my stomach, my persistent feelings of discomfort, and the need to relieve myself.

As my symptoms became worse in 1997, I frequently found myself in the emergency room, barely able to eat or drink, covered with a rash and with inflamed eyes. I lost almost all control over my bowel movements: it happened in the street, at the post office, and on the bus. These experiences were unnerving and humiliating. I ceased all activities-I stopped going to work and school and lay most of the day in bed. Every movement caused acute diarrhea. Eventually, I was completely homebound.

I was physically and emotionally depleted. The disease was out of control and so was I. I was 29, just married, and completing my master's degree when my life came to an abrupt halt. The future was vague and unimaginable.

After more than 10 weeks of hospitalization with no sign of remission, my doctors began to discuss the option of a colectomy. The surgeon was a very kind and pleasant man with a soft voice, and I immediately trusted him. He explained the procedure in detail: he would conduct 2 surgeries with a 3 -month interval between them. He did a sketch on a page with the hospital's logo to illustrate the procedure, which I treasure to this day.

I was terrified. I knew the surgery was irreversible and I could not imagine what my life without a colon would look like. Would I be able to eat normally again? Could I engage in sports? And what about other effects? My surgeon tried to ease my concerns, reassuring me that after a short while I would be able to lead a normal life and would hardly notice the absence of my colon. I believed I would return to my asymptomatic life, and perhaps he believed that, too. It would take time, and eventually my small intestine would "learn" the functions of the missing colon. "You will have a new life," he promised. I decided I had nothing to lose.

After those memorable words, I could not comprehend that it would 
take nearly 2 decades for this new life to manifest. The operations were successful, terminating the actual illness, but I now had a new complex chronic condition. The journey towards wellness and healing had only just begun; a journey that would encompass much inner and outer work. The first few years after the operations were extremely difficult. Physically, I was in survival mode, suffering from acute diarrhea and barely able to eat. I had several intestinal blockages requiring hospitalization. I was concerned and scared of the future. I was able to venture out into the world again, however, and I worked hard to become the "exemplary patient" exercising 6 times a week, working full-time, and studying for my $\mathrm{PhD}$. Yet I began to realize my over-activity stemmed from confusion and anxiety. I began seeing a medical psychologist, a crucial part of my healing journey. For the first time, with her, I could truly be weak and afraid, and didn't have to prove that I was the "star patient." Over time, I allowed myself to stop exercising so intensively, which helped me gain strength. I was slowly able to digest food.

Minute by minute, day by day, I continue to learn about the complexities of living without a colon. I navigate the quantities, the texture, and the timing of everything that I eat and drink and I make sure that I am always near a toilet. I skip any activity that could jeopardize my ability to maintain this strict regime. Leaving the house still demands precise planning. I take almost all the same drugs that I took before surgery, because apparently a body without a colon does not "forget" the rest of the symptoms of the disease.

My doctoral thesis on women suffering from fibromyalgia and chronic fatigue syndrome helped me come to understand my own condition as chronic. My identity as an individual "coping with disability" was slow to form, but when it consolidated, it helped, for I no longer had to pretend I was "normal." Since removing my colon, I am no longer ill, but I am disabled. In some ways both my accomplishments and my suffering have been greater than what others can easily notice because of the invisibility of my post-surgical condition. I had to learn to give a voice to my difficulties. I learned to set limits on my schedule and to say: "No, I can't do this."

Sharing my story with the medical world, so they could have a glimpse into the inner struggle of contending with such a complex condition also contributed to my healing. For years, I have been speaking to medical students about my coping process. Paradoxically, through revealing my weakness, exhaustion, and trauma-first to myself in therapy, and later to others, I found sustenance and liberation. I can be weak. I can be strong. I can simply be who I am.

I am currently a researcher in the field of medical anthropology and disability studies and teach medical and nursing students. My life is therefore filled with hospitals, patients, doctors, and medical stories. One of my greatest passions is for my research on coping with chronic illness. To the many voices that have told me over the years, "Move on, you're fine now, get on with your life," I answer: "This is my life. I feel I have found a wellspring from which I draw my strength for life. I love being in hospitals, researching and teaching on chronic illness and disability. It keeps me strong."

I have learned the importance of creating realistic expectations for surgery patients and preparing them both physically and psychologically for what may be a long road ahead. The patient's family physician can be a crucial support before surgery and throughout the long healing process, for the family physician can help the patient incorporate this dramatic experience into his or her life story. The details of daily life post-surgery should not be overlooked. A truly caring listening ear on the part of the doctor cannot be overestimated. The medical system gave me back my life $e_{\text {I }}$ wanted to share the story of this new life with them. Sharing these words here is also a significant part of my healing.

Two decades after the surgeries, I am still asked: "Would you have surgery again?" Yes. I certainly would. The operations were a crucial step towards regaining the ability to live a full life. The management of daily life after such a procedure, however, is more than the remediation or transformation of symptoms; it requires much physical readjustment as well as a much broader transformation of the self.

I am constantly amazed at the flexibility of both my body and soul as I continue to travel this pathless trek into the unknown. Every day when I walk into the hospital where I work is a triumph. I still never know if the day will end in hospitalization. Each morning I awaken to my new life, creating and embracing it with all of its uncertainty, vulnerability, and helplessness, as well as all of its excitement, passion, and gratitude for life. My life with a disability has directed my personal and professional attention towards my specific field of work. Perhaps this is not what my surgeon intended or meant when he promised me a new life, but this is what has become of that prophecy from over 20 years ago.

To read or post commentaries in response to this article, see it online at http://www.AnnFamMed.org/content/16/2/166.

Key words: ulcerative colitis; colectomy; illness experience; healing

Submitted March 12, 2017; submitted, revised, August 7, 2017; accepted September 13, 2017.

Acknowledgments: These ideas developed during my time as a visiting scholar at the University of California, Berkeley. I would like to thank Prof. Georgina Kleege and Kaitlin Kimmel for our long conversations that encouraged me to write down my memories. I am incredibly grateful to Dr. Ruth Kannai, and other friends $\varepsilon$ colleagues for their comments. Finally, I wish to thank Aya Alon for her sensitive and wise editing. 